\title{
Factors of Affecting Internal Control Benefits under ERP System An Empirical Study in Taiwan
}

\author{
Hsing-Hwa Hsiung ${ }^{1}$ \& Juo-Lien Wang ${ }^{1}$ \\ ${ }^{1}$ Department of Accounting, Chaoyang University of Technology, Taichung, Taiwan, ROC \\ Correspondence: Juo-Lien Wang, Department of Accounting, Chaoyang University of Technology, 168, Jifeng E. \\ Rd., Wufeng District, Taichung, 41349 Taiwan, R.O.C. Tel: 886-4-2332-3000. E-mail: lotuswang@cyut.edu.tw
}

Received: January 14, 2014

Accepted: February 8, 2014

Online Published: March 26, 2014

doi: 10.5539/ibr.v7n4p31

URL: http://dx.doi.org/10.5539/ibr.v7n4p31

\begin{abstract}
Implementation of an ERP system has become an inevitable trend in modern enterprises. The smooth performance of daily operations and successful reduction of operational risks for an enterprise depend on the implementation of a sound internal control mechanism. Referencing literature and recruiting internal auditors of Taiwan Stock Exchange (TWSE)/Gre Tai Securities Market (GTSM)-listed companies and emerging stock companies, this study investigates the factors that influence the internal control benefits (based on COSO) of an enterprise in an ERP system environment. The results indicate that (1) critical factors that influence the internal control benefits of an enterprise include various ERP quality variables, such as system and information quality, service quality, and internal control quality. Good communication quality can enhance the internal control benefits. (2) The extent of implementation and the internal control benefits of an enterprise are positively correlated. The implementation of internal controls with an ERP equipped with an internal control mechanism improves the internal control benefits of an enterprise.
\end{abstract}

Keywords: ERP systems, internal control, COSO, information success model

\section{Introduction}

Numerous enterprises suffered great losses and collapsed in recent years because of a failure to implement internal controls or because of a poorly designed internal control system. Consequently, issues regarding internal control and corporate governance have attracted substantial attention and responses from industries, government, and academia. An internal control system is a vital mechanism that enables an enterprise to achieve its operational goals, improves operational efficiency, strengthens its corporate constitution, and enhances its competitiveness. Smooth implementation of daily operations and successful reduction of operational risks in an enterprise rely on the implementation of a sound internal control mechanism.

Taiwan has the perfect information infrastructure. Faced with a complex and changeable business environment, enterprises rely on information technology to integrate their operations for substantial development. According to a survey of large enterprises in Taiwan (the top 1,000 manufacturers, top 500 service industries, and top 100 financial firms) conducted by the Institute for Information Industry in 2010, the enterprise resource planning (ERP) system establishment rate was approximately $78 \%$, of which, manufacturers accounted for as high as $90 \%$ (Note 1). This data implies that ERP systems are critical to manufacturers for improving process efficiency. The operational mode of ERP systems differs from that of traditional manual operation systems; enterprises must re-evaluate risks associated with ERP implementation and establish response measures. Therefore, enabling enterprises to implement internal controls and strengthen their corporate constitution through an ERP equipped with an internal control mechanism has become a crucial issue.

Early studies on ERP were primarily conducted from the perspective of "implementation," such as the benefits and key success factors of ERP implementation (Markus et al., 2000; Al-Mashari et al., 2003), a balanced scorecard-based framework, and ERP-related studies (Chand et al., 2005). With the popularization of ERP, research directions have gradually diversified in recent years. Of the related topics, ERP and internal control benefits are essential issues. Recent studies on whether ERP implementation can strengthen internal control mechanisms were based on case studies and focused on how an enterprise can implement internal control designs and inspections in an ERP environment. Few studies used large samples to investigate whether an enterprise can strengthen and improve its internal control functions, or discussed the benefits of an ERP system 
from the perspective of internal control (Poston \& Grabski, 2001; Bradford \& Florin, 2003).

Academia holds different views on whether ERP implementation can improve internal control benefits (Hunton et al., 2006; Lambert, 2001). The reason for the inconsistency is that although ERP implementation has a positive effect on benefit enhancement, it also has proxy problems, namely, deliberate manipulation of business operators. Thus, these positive and negative effects render the outcomes unclear. Another major cause of the ambiguity is the lack of a reliable and valid index scale for internal control benefits. Therefore, we developed 10 questions related to information systems based on the five main internal control factors (Note 2) published by the Committee of Sponsoring Organizations of the Treadway Commission (COSO) to measure the internal control benefits in enterprises after ERP implementation. The outcomes of this study may enable wider applications for future academic research.

Additionally, Section 404 of the Sarbanes Oxley Act emphasizes the importance of internal control in information systems. Taiwan also stipulates that the operation procedure of an ERP system must comply with the "Regulations Governing Establishment of Internal Control Systems by Public Companies" to prevent errors and fraudulent operating activities during each transaction cycle. Additionally, most ERP systems have control functions installed in the control points of each transaction cycle. However, if an internal auditor does not agree with or is not aware of these functions and does not implement the internal control mechanism, the benefits of the relevant internal control functions in ERP systems may not be fully realized. Few studies have explored the effect of the internal control mechanism of ERP implementation on the internal control benefits. Therefore, this study adopts the 11 control operations types that must be included in an information system for measuring the extent of internal control implementation, as stipulated in Article 8 of the Regulations Governing Establishment of Internal Control Systems by Public Companies, to investigate the relationship between the ERP internal control mechanism and internal control benefits.

In summary, we surveyed internal auditors of Taiwan Stock Exchange (TWSE)/Gre Tai Securities Market (GTSM)-listed companies and emerging stock companies to investigate key factors that influence internal control benefits under an ERP system environment. By identifying and understanding influential factors, we anticipate that with a changing enterprise information environment, ERP systems can achieve the functions and benefits of internal control, enhance surveillance potency, eliminate inappropriate employee behavior, and promote and implement corporate governance.

\section{Literature Review and Hypothesis Construction}

\subsection{Early ERP Research}

Most early ERP studies focused on how ERP could be successfully implemented, the factors for successful ERP implementation (Markus et al., 2000; Al-Mashari et al., 2003), and the benefits of ERP (Chand et al., 2005); the foci here refer to the selection and use of effective indicators. Currently, key factors for successful implementation include correct business operating models, senior management support, appropriate promotional strategy, careful selection of outsourced information technology companies, high employee information literacy, and use of external resources. Indicators of ERP effectiveness include various financial indicators, productivity indicators, and the satisfaction level of participants.

Theoretically, the main objectives of ERP are to effectively integrate the internal resources and business processes of an enterprise or organization to increase the efficiency of business operations and enhance the competitiveness using information technology. However, different evaluation methods lead to inconsistent empirical outcomes for ERP benefits. Most of the empirical studies conducted in the 1980s and 1990s evaluated ERP benefits based on the production efficiency of economic theories; however, these studies were unable to prove that implementing ERP could enhance the output performance of an enterprise. This phenomenon is called productivity paradox in academia. Brynjolfsson (1993) inferred three potential causes for a productivity paradox: (1) incorrect measuring indices for investments and performances; (2) time-deferred benefits were not valued; and (3) the redistribution of IT benefits was incorrectly evaluated; for example, the benefits of reduced production costs because of IT, reduced selling prices, and direct consumer benefits were not included in when assessing enterprise benefits.

Subsequently, scholars evaluated the benefits of ERP implementation in enterprises with non-productive efficiency indicators; the outcomes indicated that the non-productive efficiency was positively correlated with ERP implementation. Eakin (2002) and Dos et al. (1993) investigated the relationship between ERP implementation and stock returns using the event study method of financial theory. The results of both studies showed a positive correlation between ERP implementation and stock returns. That is, when an enterprise announces plans to establish an ERP, the stock price of the enterprise has an excess return shortly after the 
announcement. Hayes et al. (2001) introduced control variables, such as company scale, into the event study model, and the result still agreed with that of the studies mentioned above. Hunton et al. (2002) introduced analysts' earnings forecasts after ERP implementation as independent variables to investigate the effect of ERP implementation. The results also suggested that a positive correlation between ERP implementation and benefits exists.

A number of scholars used traditional financial accounting ratios as performance indicators for ERP implementation. Poston and Grabski (2001) selected 50 companies as samples and used four categories of financial ratios as variables to investigate the growth of an enterprise before and after implementing ERP. The results indicated that although revenues created by each employee increased and the costs of goods sold decreased annually, ERP implementation did not reduce distribution costs or increase residual income. Brynjolfsson and Hitt (1996) interpreted this phenomenon to mean the benefits obtained from enhanced employee performance following ERP implementation were directly returned to customers; thus, the benefits could not be recorded in the quantifiable trading figures of an enterprise.

In addition to evaluating the benefits of ERP implementation with quantitative indicators, the use of a qualitative satisfaction indicator is also an important method for evaluating the success of an information system. Bailey and Pearson (1983) interpreted user satisfaction as an "attitudinal" response. High user satisfaction is typically an indication of a highly efficient information system (Ives et al., 1983; Baroudi \& Orlikowski, 1988); that is, users believe that an information system that can fulfill their needs for information and benefits can be acquired. Currently, most studies regarding satisfaction with information systems focus on two user categories: end users and developers of information systems. Few studies have examined the satisfaction of internal auditors regarding the "anti-fraud function" of an ERP system from the perspective of the internal control of an enterprise.

\subsection{Information Success Model}

Because the effectiveness and success/failure of information system implementation not only affects the information management strategies of an enterprise, but also influences the direction of information investment, DeLone and McLean (1992) proposed a key factor model that affects information system success. Subsequently, information system success models have become a prominent topic, and related studies are continuously published. Considering the changing social information environment, DeLone and McLean (2003) reviewed more than 60 conceptual and empirical journals and proceedings (Note 3) on information management systems that were written more than 10 years after the model was proposed. Then, they developed an updated universal information system success model. This universal model, named the D\&M information system success model, described the direct or indirect effects of five dimensions on the net benefits of information systems. These five dimensions included information quality, system quality, service quality, use intention, and user satisfaction. These qualities were critical variables that affected the net benefits of an information system. Based on this theory, we hypothesize that the quality of an ERP system affects the internal control benefits.

The universal model contains six dimensions: (1) information quality, which refers to the output qualities and includes the accuracy, completeness, clarity, liquidity, timeliness, relevance, usefulness, ease of comprehension, conciseness, reliability, updatedness, and objectivity of an information system; (2) system quality, which refers to the quality of an information system and includes ease of operation, ease of use, ease of learning, functional usefulness, accuracy, flexibility, integration, and efficiency; (3) service quality, which refers to the degree of support provided by information system suppliers and service capabilities for system correction; (4) use intention, which refers to the strength of users' spontaneous plans to use an information system, or in other words, the subjective probability of an individual's desire to use an information system; (5) user satisfaction, which refers to user satisfaction of an information system and is general indicated by users' satisfaction with the system interface, software, hardware, and decision provision; and (6) net benefits, which refers to benefits associated with an information system, including tangible and intangible benefits; however, different information systems have different benefit indicators.

Although DeLone and McLean $(1992,2003)$ stated that the three qualities of an information system, information quality, system quality, and service quality, were antecedent factors for use intention, a number of scholars, for example, Jeong and Lambert (2001), combined these three factors into a single dimension to investigate the relationship between these dimensions and use intentions. However, assessing the quality of an information system by verifying the discriminant and convergent validity of these three factors through factor analysis is a more practical approach.

As an enterprise manages and invests in activities related to an information system, the level of efficiency value depends on the success or failure of the system; therefore, the success or failure of an information system is vital 
to an enterprise. Consequently, various related studies have widely applied numerous information system success models, such as ERP systems, government and public sector information systems, online trading systems, accounting information systems, medical systems, decision-management systems, e-commerce sites, business intelligence systems, and knowledge-management systems. A number of these studies adopted identical dimensions to those of D\&M information system success models (Rai \& Welker, 2002). However, most studies made partial modifications in response to the characteristics of an information system. DeLone and McLean $(1992,2003)$ did not oppose such modifications and highlighted that because the purposes of use and the users differed, the success models for different information systems would differ accordingly.

\subsection{Hypothesis Construction}

Information system success models verify that an information system has the characteristics of accuracy, completeness, clarity, usefulness, understandability, timeliness, conciseness, reliability, updatedness, objectivity, ease of operation, ease of use, ease of learning, functional usefulness, flexibility, and efficiency of information. DeLone and McLean $(1992,2003)$ and Rai and Welker (2002) contended that the system and information qualities of an information system affect the net benefits of the information system. Because an ERP allows immediate and online trading, auditing is no longer restricted by regions, time, and space; therefore, we propose Hypothesis $\mathrm{H}_{1}$ as follows:

\section{$\mathrm{H}_{1}$ : The system and information qualities of an ERP are positively correlated with internal control benefits.}

DeLone and McLean (2003) added the effect of service quality on information benefits to the updated D\&M information system success model. Service qualities include the customized modification capabilities and technical capabilities of computer centers. Service qualities refer to the degree of support and service capabilities for system correction of an information system supplier. Because internal auditing is unique, and different enterprises have different internal auditing requirements, a rigid ERP system would not fulfill the needs of internal auditing. Therefore, suppliers of ERP systems must provide appropriate customized support services to satisfy the needs of enterprise users. Thus, we propose Hypothesis $\mathrm{H}_{2}$ as follows.

\section{$\mathrm{H}_{2}$ : The service qualities of an ERP are positively correlated with internal control benefits.}

Furthermore, numerous studies (Debreceny et al., 2005; Ragowsky \& Adams, 2005) described an ERP system as an information management system that provides optimal management resources. An ERP system can integrate various upstream and downstream procedures to enhance the scalability of an enterprise. The implementation of ERP system can prevent fraudulent activity, reduce enterprise risks through mutual inspections, and provide additional auto-test functions to strengthen internal quality control. Therefore, we propose Hypothesis $\mathrm{H}_{3}$ as follows:

\section{$\mathrm{H}_{3}$ : The internal control qualities of an ERP are positively correlated with the internal control benefits.}

Newstrom and Keith (1989) defined communication as an effective strategy for providing information, facilitating mutual understanding among employees, boosting employee emotions, increasing teamwork, improving employee satisfaction, and effectively enhancing organization performance. Richman and Farner (1975) defined communication as a significant process involving the transfer of messages, facts, opinions, concepts, or feelings of a person or several people to another person or a group of people through written or spoken language, or non-language formats.

In this study, communication quality refers to communication between internal control personnel and an ERP project group; it includes communication with ERP project groups, knowledge regarding an ERP system, education and training, and the acceptability of a manual. Wright and Wright (2002) found that although an ERP system had an internal auditing design, the internal control benefits may not be realized if internal control personnel misunderstand or fail to understand the functions. Therefore, we believe that by eliminating misunderstandings and promoting trust, a good communication model enables internal auditors to fully apply their professional knowledge for existing risks and managing future risks in an enterprise. Consequently, through using an ERP system, an enterprise may gain control of its risk management and the planning of its governance system. Accordingly, we proposed Hypothesis $\mathrm{H}_{4}$ as follows:

\section{$\mathrm{H}_{4}$ : The quality of communication using an ERP is positively correlated with internal control benefits.}

Little and Best (2003) reasoned that although control functions are installed at the control points of a transaction cycle for an individual ERP system, the benefits of ERP-related internal control functions may not be fully conveyed if an internal auditor does not agree with or is unaware of these functions. Implementing internal controls using an ERP system with an internal control system can improve the internal control benefits of an 
enterprise; therefore, we proposed Hypothesis $\mathrm{H}_{5}$ as follows:

\section{$H_{5}$ : The extent of internal control implementation under an ERP structure is positively correlated with internal control benefits.}

\section{Research Methodology}

\subsection{Data Source and Sample Construction}

We adopted closed questionnaires to facilitate data calculation and quantification. We referenced the updated information system success model proposed by DeLone and McLean (2003) and the variable structure of user satisfaction with information systems proposed by Bailey and Pearson (1983) in this study. Additionally, we considered regulations regarding internal control mechanisms and studies relevant to ERP system and internal control when determining the content of the questionnaire. This study was conducted in two stages. During the first stage, we proposed a preliminary research structure and initial content for the questionnaire based on literature. Questionnaires were distributed in the second stage. First, a pretest was conducted to ensure that the designed questions conformed to the topic and scope of this study, unnecessary questions were deleted. A formal survey was conducted after the questions were finalized. The questionnaire adopted a five-point Likert scale and was designed to include the three main dimensions of this study: quality variables of an ERP system, the extent of internal control implementation under an ERP environment, and the internal control benefits of an ERP system. Respondents were instructed to score the questions; a high score indicates that the quality was high, whereas a low score indicates that the quality was low.

The primary research subjects of this study were internal auditors randomly selected from TWSE/GTSM-listed and emerging stock companies. To ensure the effectiveness of the recovered samples, questionnaires were recovered approximately three months after distribution. Under the same considerations, a pretest was conducted. During the pretest, 60 questionnaires were distributed, 35 of which were recovered. Unnecessary questions that were identified through reliability and validity analyses were eliminated from the final questionnaire. Subsequently, 350 finalized questionnaires were formally distributed among randomly selected subjects. We recovered 147 questionnaires, of which, 25 were invalid and eliminated. Thus, 122 valid questionnaires were obtained for an effective recovery rate of $34.86 \%$.

\subsection{Operational Definitions and Questions for Dependent and Independent Variables}

We allocated each of the dimensions in the research model an operational definition and developed measuring questions according to relevant literature. These measuring questions are listed in Tables 1 and 2.

(1) Dependent variables: indicators for internal control benefits

We developed 10 questions that were related to information systems based on the five main internal control factors (Note 4) published by the COSO to measure the internal control benefits of ERP implementation in enterprises. Indicators for this dimension were also developed based on the factor scores obtained from factor analyses. The measuring questions for the dimension are listed in Table 1.

Table 1. Questions for measuring dependent variables

The internal control benefits of an ERP system (dependent variables)

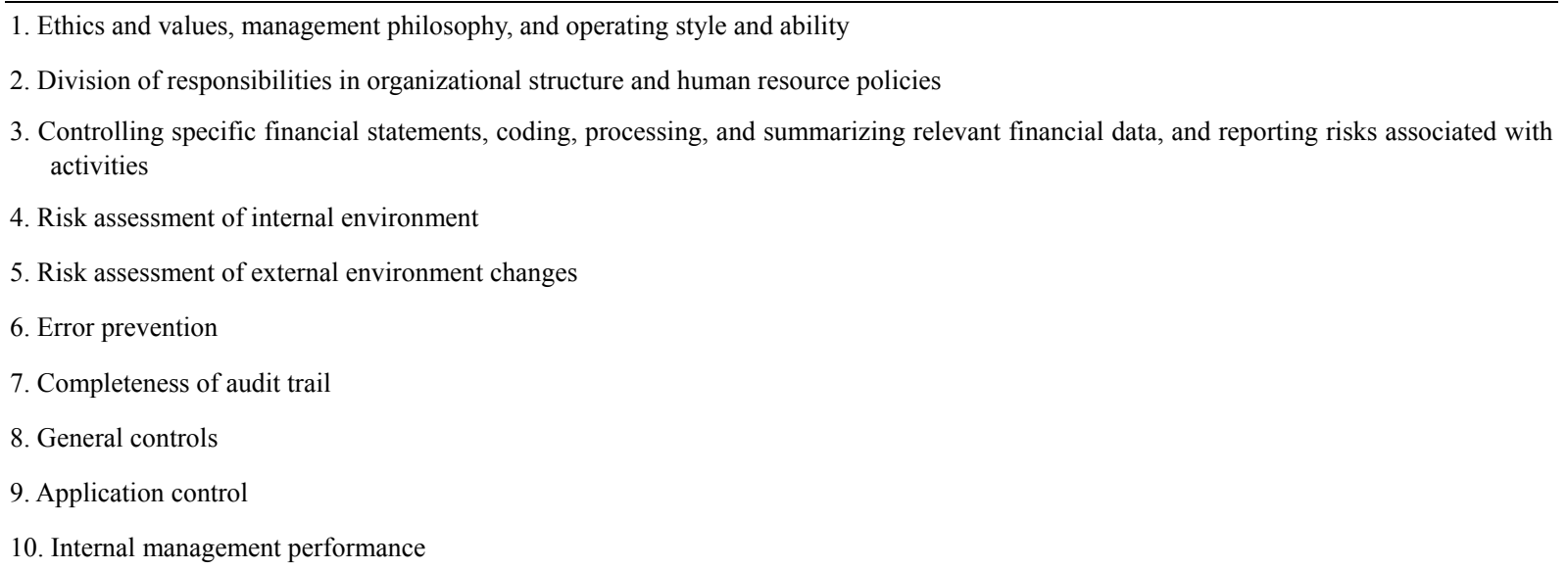

Reference source: The five main internal control factors published by the COSO. 


\section{(2) Independent variable}

We designed a questionnaire to measure ERP quality variables and the extent of internal control implementation. The measurement questions for the independent variables are shown in Table 2. Four major quality factors and factors for the extent of internal control implementation were extracted through factor analyses. Indicators for this dimension were developed based on the factor scores obtained from factor analysis. The operational definitions for the independent variables are as follows:

1) System and information quality: refers to the quality of information systems, such as ease of operation, ease of use, ease of learning, functional usefulness, accuracy, flexibility, integration, and efficiency.

2) Service quality: refers to the degree of support and service capabilities for system corrections of information system suppliers.

3) Internal control quality: refers to internal control functions provided by an ERP system.

4) Communication quality: refers to the communication between internal control personnel and ERP system suppliers or project groups.

5) The extent of ERP internal control implementation: facilitates the effective operation and function performance at all enterprise levels during the automated working process, and employs online real-time monitoring to understand the effectiveness of internal controls. We adopted the 11 control operation types that Article 8 of the Regulations Governing Establishment of Internal Control Systems by Public Companies stipulates must be included in an information system as the measuring questions.

Table 2. Measuring questions for independent variables

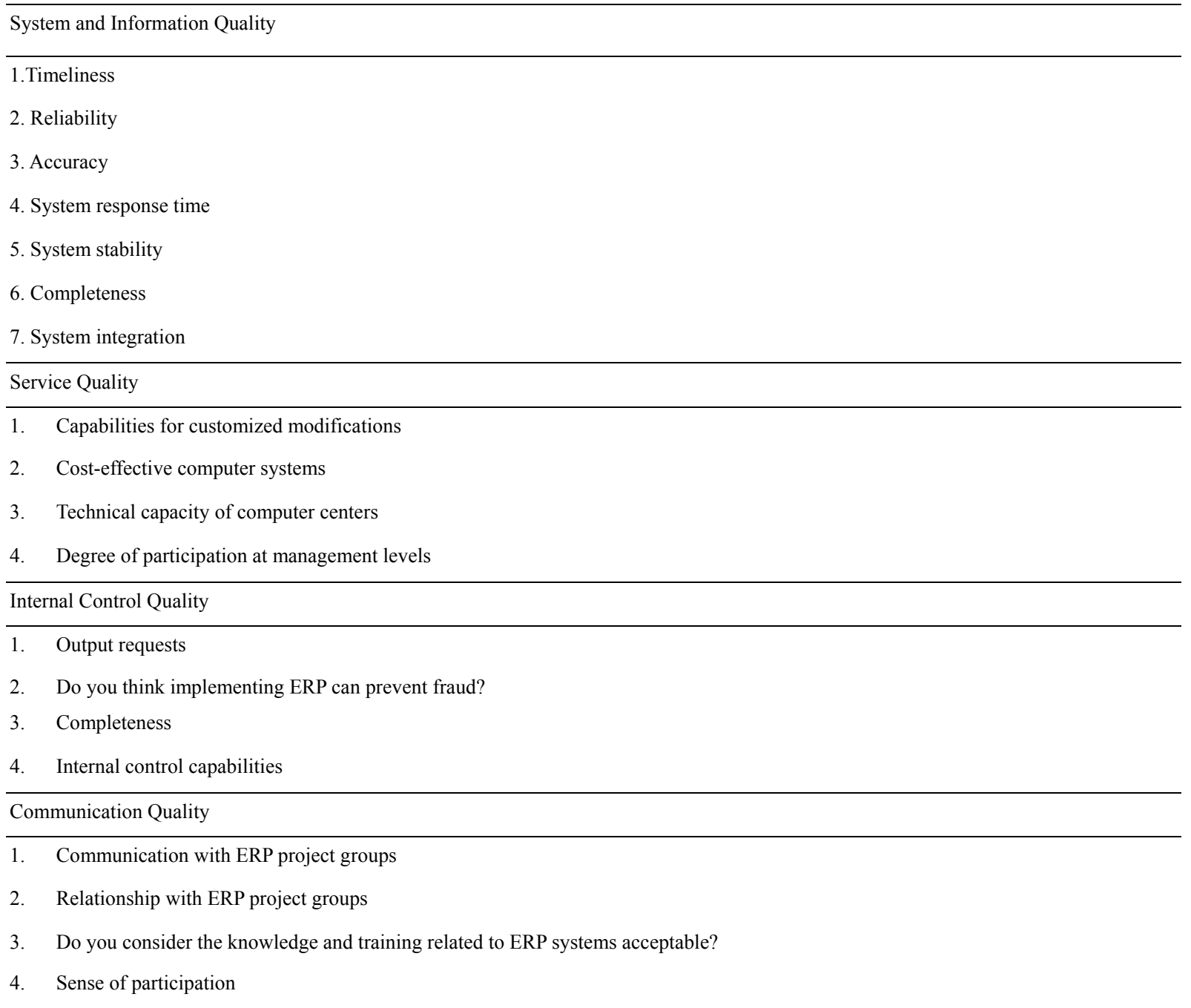


5. Are you satisfied the function introduction, system files, and user manual of ERP systems?

6. The industry knowledge of ERP project groups

7. The attitude of ERP project groups

8. Understanding of the system

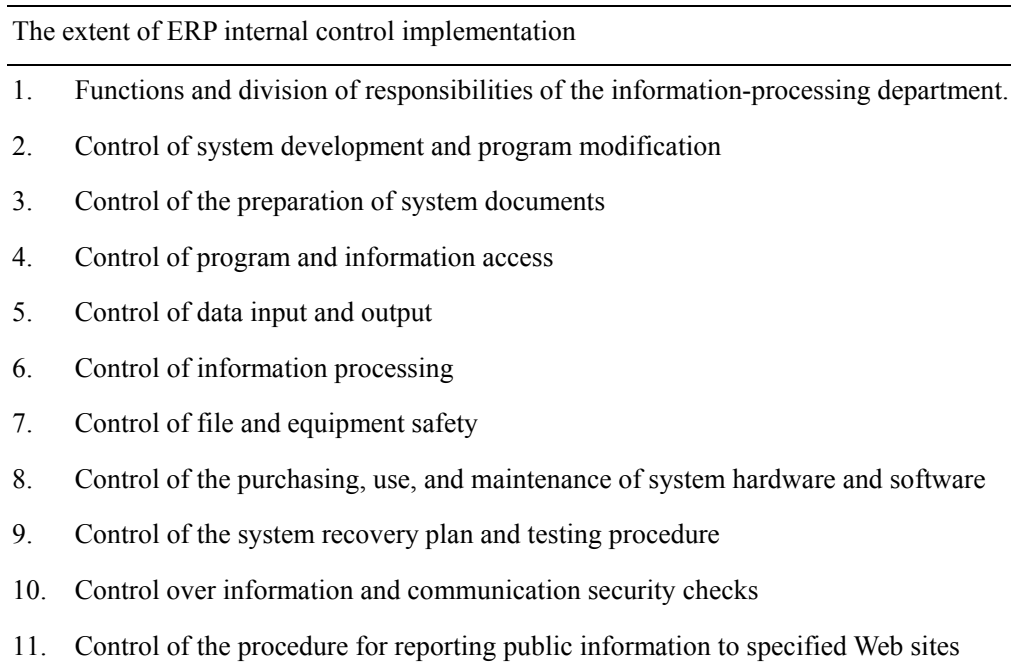

(3) Variables of internal auditor characteristics

To improve the explanatory power of the research model, three respondent characteristics were considered: gender, level of education, and the duration of internal auditing participation.

(4) Variables of enterprise characteristics

To improve the explanatory power of the research model, five enterprise characteristic variables were considered: the industry category, type of ERP system implemented, duration of ERP implementation, the length of time since the completion of ERP implementation, and the listed category of an enterprise.

3.3 Establishment of Empirical Models

The regression models established for validating hypotheses $\mathrm{H}_{1}$ to $\mathrm{H}_{5}$ proposed in this study are presented below.

Model 1: Overall model that contains all variables

$E F F E C T=\beta_{0}+\beta_{1} S Y S Q+\beta_{2} S E R V I C E Q+\beta_{3} I C Q+\beta_{4} C O M M Q+\beta_{5} I M P+\beta_{6} S E X+\beta_{7} E D U+\beta_{8}$ WYEAR $+\beta_{9} I N D U+$ $\beta_{10} C A T+\beta_{11}$ TIME $+\beta_{12}$ PERIOD $+\beta_{13}$ LIST $+\beta_{14} C Y+\varepsilon$

Model 2: The overall model with the characteristic variables of the respondents and enterprises excluded $E F F E C T=\beta_{0}+\beta_{1} S Y S Q+\beta_{2}$ SERVICEQ $+\beta_{3} I C Q+\beta_{4} C O M M Q+\beta_{5} I M P+\varepsilon$

Model 3: The overall model containing only the respondent characteristic variables

$E F F E C T=\beta_{0}+\beta_{1} S Y S Q+\beta_{2} S E R V I C E Q+\beta_{3} I C Q+\beta_{4} C O M M Q+\beta_{5} I M P+\beta_{6} S E X+\beta_{7} E D U+\beta_{8}$ WYEAR $+\varepsilon$

Model 4: The overall model containing only the enterprise characteristic variables

EFFECT $=\beta_{0}+\beta_{1} S Y S Q+\beta_{2} S E R V I C E Q+\beta_{3} I C Q+\beta_{4} C O M M Q+\beta_{5} I M P+\beta_{9} I N D U+\beta_{10} C A T+\beta_{11} T I M E+\beta_{12}$ PERIOD $+\beta_{13}$ LIST $+\beta_{14} C Y+\varepsilon$

The variables are defined as follows:

EFFECT: internal control benefits based on COSO under an ERP system environment;

SYSQ: system and information quality;

SERVICEQ: service quality;

ICQ: internal control quality;

COMMQ: communication quality;

IMP: the extent of ERP internal control implementation; 
SEX: gender;

EDU: respondents' level of education;

WYEAR: the number of years respondents participated in internal auditing;

INDU: industry category;

CAT: type of ERP system implemented;

TIME: duration of ERP implementation;

PERIOD: the length of time since the completion of ERP implementation;

LIST: TWSE-, GTSM-listed companies, or emerging stock companies;

CY: the number of years since the establishment of an enterprise.

\section{Data Analysis and Results}

\subsection{Descriptive Statistical Analysis of Samples}

The majority of the respondents were women (82), accounting for $67.2 \%$ of the effective samples; 40 respondents were men, accounting for $32.8 \%$ of the effective samples. Additionally, 83 respondents $(68.03 \%)$ had college degrees, and 28 had graduate degrees (22.95\%). The number of respondents involved in internal auditing for less than five years was 47 , and the number involved for six to ten years was 40 . Regarding the distribution of industry categories, the electronics industry accounted for the majority of the enterprises surveyed (79 enterprises), followed by traditional industries (41 enterprises). Most of the enterprises surveyed were listed companies (65; accounting for $53.28 \%$ of all enterprises surveyed), followed by over-the-counter companies. Finally, for the ERP systems implemented in enterprises, 29 enterprises used SAP system, and 37 used Data systems.

\subsection{Reliability Analysis}

The reliability analysis results for the dependent and independent variables are shown in Table 3. Cronbach's $\alpha$ coefficient was 0.89 for the internal control benefits of an ERP system (dependent variable), 0.91 for the extent of ERP internal control implementation, and between 0.81 and 0.91 for the four quality scales of ERP systems. The results indicate that the overall questionnaire and various sections of the questionnaire are highly consistent and stable; therefore, the questionnaire is reliable.

Table 3. Cronbach's $\alpha$ reliability analysis

\begin{tabular}{lcc}
\hline Dimension & \# items & Cronbach's coefficient \\
\hline Internal control benefits of ERP system & 10 & 0.89 \\
System and information quality & 7 & 0.89 \\
Service quality & 4 & 0.85 \\
Internal control quality & 4 & 0.81 \\
Communication quality & 8 & 0.91 \\
The extent of ERP internal control implementation & 11 & 0.91 \\
\hline
\end{tabular}

\subsection{Validity Analysis}

For convergent validity, we examined the correlation of each question with the other questions using factor analysis. The quality of each item in an ERP system was factor-extracted using principal component analysis and a maximum variation approach. The KMO value was 0.887 , and the significance of the Bartlett's test of sphericity approached 0 ; these results indicate that the questionnaire is appropriate for factor analysis. The test results are shown in Table 4.

To examine the discriminant validity, we adopted the Pearson's correlation coefficient $(\gamma)$ to assess whether the correlation coefficients of the factors in the correlation matrix were greater than 0.8 or 0.9 . The correlation analysis results are shown in Table 5. The correlation coefficients of all factors were between 0.07 and 0.46 ; thus, the correlation is positive and minimal. 
Table 4. KMO test results

\begin{tabular}{ll}
\hline Kaiser-Meyer-Olkin Measure of Sampling Adequacy & 0.887 \\
Bartlett's test of sphericity & 2063.689 \\
Degree of freedom & 300 \\
Significant value & 0.000 \\
\hline
\end{tabular}

Table 5. Pearson's correlation coefficient results

\begin{tabular}{|c|c|c|c|c|c|c|}
\hline & EFFECT & IMP & COMMQ & SYSQ & SERVICEQ & ICQ \\
\hline EFFECT & 1.0000 & - & - & - & - & - \\
\hline IMP & $0.4599 * * *$ & 1.0000 & - & - & - & - \\
\hline COMMQ & $0.2844 * * *$ & $0.2251^{* * *}$ & 1.0000 & - & - & - \\
\hline SYSQ & $0.2146^{* *}$ & $0.3692 * * *$ & $0.1644 *$ & 1.0000 & - & - \\
\hline SERVICEQ & $0.2442 * * *$ & $0.3017 * * *$ & 0.0461 & 0.0785 & 1.0000 & - \\
\hline ICQ & $0.4248 * * *$ & $0.2086^{* *}$ & 0.1222 & 0.0182 & 0.0710 & 1.0000 \\
\hline
\end{tabular}

Note. $* *=P<.01 ;$ and $*=P<.05$.

\subsection{Hypothesis Validation}

Table 6 shows the regression analysis result. By testing Hypotheses $\mathrm{H}_{1}$ to $\mathrm{H}_{5}$ with Model 1, was found that this regression model had a satisfactory goodness-of-fit ( $F$-value was 6.1011, $P$-value approaches 0$)$; the overall explanatory power was $44.9 \%$. The four quality variables of the ERP system (the system and information quality, service, internal control, and communication) were positively correlated with indicators of internal control benefits (the regression coefficients for these variables were $0.1562,0.1431,0.4071$, and 0.1484 ). These results support Hypotheses $\mathrm{H}_{1}$ to $\mathrm{H}_{4}$ proposed in this study. These hypotheses propose that the system and information quality variables, that is, the information success model developed by DeLone and Mclea $(1992,2004)$, are critical influence factors for internal control benefits.

Additionally, the extent of internal control implementation had a significantly positive correlation with internal control benefits (the regression coefficient was 0.3202). This result supports Hypothesis $\mathrm{H}_{5}$ proposed in this study and demonstrates the influence of implementing ERP internal control functions and mechanisms on the internal control benefits. The effect of following the information system control criteria stipulated in Article 8 of the Regulations Governing Establishment of Internal Control Systems by Public Companies on the internal control benefits of an enterprise was substantial and far-reaching.

Furthermore, the correlations among the respondents' characteristic variables (gender, level of education, and years involved with internal auditing) and the internal control benefits were statistically insignificant. The correlations among the enterprise characteristic variables (industry category, type of ERP system implemented, duration of ERP implementation, time since the completion of ERP implementation, and the listed category) and the internal control benefits of an enterprise were also statistically insignificant. In other words, the respondent and enterprise characteristics have no effect on the internal control benefits.

Finally, to increase the robustness of this study, we examined Hypotheses $\mathrm{H}_{1}$ and $\mathrm{H}_{4}$ using Model 2 (the overall model excluding the characteristic variables of the respondents and enterprises), Model 3 (the overall model excluding the enterprise characteristics), and Model 4 (the overall model excluding the respondent characteristics). The results are identical to that provided by Model 1; however, the correlations between service quality and internal control benefits in Models 2 and 3 were reduced. Among these four models, the adjusted $\mathrm{R}^{2}$ value was the lowest for Model 1 (0.3750) and the highest for Model $2(0.4000)$, indicating that the regression model Model 2 has the greatest explanatory power and the best goodness-of-fit for internal control benefits. This result is consistent with that of the information system success model, where the characteristic variables of the respondents and enterprises are excluded. 
Table 6. Results of regression analysis

\begin{tabular}{|c|c|c|c|c|c|c|c|c|}
\hline & \multicolumn{2}{|c|}{ Model 1} & \multicolumn{2}{|c|}{ Model 2} & \multicolumn{2}{|c|}{ Model 3} & \multicolumn{2}{|c|}{ Model 4} \\
\hline & coefficient & $\mathrm{t}$ value & coefficient & $\mathrm{t}$ value & coefficient & t value & coefficient & $\mathrm{t}$ value \\
\hline \multirow[t]{2}{*}{ intercept } & -0.1820 & \multirow[t]{2}{*}{-0.2023} & 0.0048 & \multirow[t]{2}{*}{0.0675} & & \multirow[t]{2}{*}{0.8323} & -0.5942 & \multirow[t]{2}{*}{-1.0013} \\
\hline & $(0.8997)$ & & $(0.0706)$ & & $(0.5096)$ & & $(0.5935)$ & \\
\hline \multirow{2}{*}{$\operatorname{SYSQ}\left(\beta_{1}\right)$} & 0.1562 & \multirow[t]{2}{*}{$1.8889^{*}$} & 0.1342 & \multirow[t]{2}{*}{$1.7091^{*}$} & 0.1366 & \multirow[t]{2}{*}{$1.7194 *$} & 0.1556 & \multirow[t]{2}{*}{$1.9101^{*}$} \\
\hline & $(0.0827)$ & & $(0.0785)$ & & $(0.0794)$ & & $(0.0815)$ & \\
\hline \multirow{2}{*}{ SERVICEQ $\left(\beta_{2}\right)$} & 0.1431 & \multirow{2}{*}{$1.6241^{*}$} & 0.1034 & \multirow{2}{*}{1.3635} & 0.1000 & \multirow{2}{*}{1.2375} & 0.1468 & \multirow{2}{*}{$1.7583^{*}$} \\
\hline & $(0.0881)$ & & $(0.0758)$ & & $(0.0808)$ & & $(0.0835)$ & \\
\hline \multirow{2}{*}{$\mathrm{ICQ}\left(\beta_{3}\right)$} & 0.4071 & \multirow{2}{*}{$5.3256^{* * *}$} & 0.4009 & \multirow{2}{*}{$5.5937 * * *$} & 0.4097 & \multirow{2}{*}{$5.6104 * * *$} & 0.4045 & \multirow{2}{*}{$5.3600 * * *$} \\
\hline & $(0.0764)$ & & $(0.0717)$ & & $(0.0730)$ & & $(0.0755)$ & \\
\hline \multirow{2}{*}{$\operatorname{COMMQ}\left(\beta_{4}\right)$} & 0.1484 & \multirow[t]{2}{*}{$1.7737^{*}$} & 0.1669 & \multirow[t]{2}{*}{$2.2509 * *$} & 0.1753 & $2.2919 * *$ & 0.1490 & $1.8630^{*}$ \\
\hline & $(0.0836)$ & & $(0.0741)$ & & $(0.0765)$ & & $(0.0800)$ & \\
\hline & 0.3202 & & 0.3127 & & 0.3072 & & 0.3178 & \\
\hline $\operatorname{IMP}\left(\beta_{5}\right)$ & $(0.0948)$ & $3.3794 * * *$ & $(0.0862)$ & $3.6258^{* * *}$ & $(0.0889)$ & $3.4551^{* * * *}$ & & $3.4515^{* * *}$ \\
\hline$S F Y(\beta)$ & -0.0461 & 02668 & & & -0.0997 & 06174 & & \\
\hline $\mathrm{SE} \Lambda\left(\mathrm{p}_{6}\right)$ & $(0.1728)$ & -0.2000 & & & $(0.1615)$ & $-0.61 / 4$ & & \\
\hline$F D U\left(\beta_{-}\right)$ & -0.0731 & 0.5641 & & & -0.0865 & 07027 & & \\
\hline (P) & $(0.1296)$ & -0.5041 & & & $(0.1229)$ & -0.1031 & & \\
\hline & -0.0325 & & & & 0.0086 & & & \\
\hline (1) & $(0.0838)$ & (-5070 & & & $(0.0773)$ & 0.1109 & & \\
\hline INDU $\left(\beta_{8}\right)$ & 0.2046 & 13057 & & & & & 0.2006 & 1.3154 \\
\hline 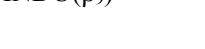 & $(0.1567)$ & 1.000 & & & & & $(0.1525)$ & \\
\hline $\operatorname{CAT}\left(\beta_{10}\right)$ & 0.0102 & 0.3263 & & & & & 0.0122 & 0.3955 \\
\hline & $(0.0314)$ & & & & & & $(0.0308)$ & \\
\hline & 0.0782 & 1070 & & & & & 0.0761 & 1.0594 \\
\hline 111VIL $(P 11)$ & $(0.0728)$ & 1.0740 & & & & & $(0.0719)$ & \\
\hline PFPIOD $\left(\beta_{1}\right)$ & -0.0683 & 07534 & & & & & -0.0627 & -0.7041 \\
\hline PEKIOD $\left(p_{12}\right)$ & $(0.0907)$ & -0.1534 & & & & & $(0.0890)$ & \\
\hline JST $\beta$ & -0.1033 & 0877 & & & & & -0.0929 & -0.8094 \\
\hline $\operatorname{LIS1}\left(p_{13}\right)$ & $(0.1177)$ & $-0.0 / 1 / 1$ & & & & & $(0.1148)$ & \\
\hline & 0.1207 & 11388 & & & & & 0.1244 & 1.3178 \\
\hline (1) & $(0.1060)$ & 1.1500 & & & & & $(0.0944)$ & \\
\hline $\mathrm{F}$ & 6.1011 & & 16.9697 & & 10.5090 & & 7.8834 & \\
\hline R square & 0.4490 & & 0.4250 & & 0.4290 & & 0.4450 & \\
\hline Ajusted R square & 0.3750 & & 0.4000 & & 0.3880 & & 0.3890 & \\
\hline
\end{tabular}

Note. ${ }^{\mathrm{P}} \mathrm{P}<0.1, * * \mathrm{P}<0.05, * * * \mathrm{P}<0.01$. 


\section{Conclusions}

ERP system implementation has been popularized at all enterprise levels. Consequently, improving the extent of internal control implementation and enhancing the corporate constitution of enterprises through an ERP system with internal control designs has become a crucial issue. Numerous studies (Debrecenty et al., 2005; Ragowsky \& Adams, 2005) have reported that these systems can prevent fraudulent behavior and reduce risks through mutual inspection and ERP implementation, improving the internal control quality of enterprises. An enterprise can increase profits and strengthen its constitution by implementing internal controls using an ERP system equipped with an internal control system. Studies on factors that affect the internal control benefits of an ERP system are limited. Therefore, we recruited internal auditors as the main research subjects to investigate the internal control benefits of ERP systems based on the information system success model.

Because scales for measuring internal control benefits and the extent of ERP internal control implementation were unavailable, we first developed 10 questions related to information systems based on the five main internal control factors (Note 4) published by the COSO to measure the internal control benefits of ERP implementation in enterprises. Additionally, we adopted the 11 control operation types that Article 8 of the Regulations Governing Establishment of Internal Control Systems by Public Companies stipulates must be included in information systems as the scale for measuring the extent of internal control implementation. This scale may have wider application in future academic studies.

In conclusion, the results of this study indicate that the quality variables of an information system, system and information quality, service quality, and internal control quality are critical factors influencing the internal control benefits of an enterprise. Good communication can also improve the internal control benefits. Enhancing the internal control personnel's understanding of an ERP system by fully explaining the functions, information qualities, and service quality of an ERP system using a good communication interface can improve the internal control benefits of an ERP system. Therefore, enhancing internal control personnel's understanding of the internal control mechanism in an ERP system is urgently required. In addition to reproducing factors in systems (information and system quality, internal control quality) and on a technical level (service quality), communication quality is critical to an ERP internal control environment. An enterprise must understand the importance of the coexistence of these factors to enhance the benefits of ERP internal controls.

Furthermore, the extent of internal control implementation and the internal control benefits of an enterprise are positively correlated. This correlation suggests that the ERP internal control benefits cannot be fully realized if the internal auditors of an enterprise that implements an ERP system do not apply these functions, regardless of whether an ERP system is equipped with control functions to control a transaction cycle. Therefore, internal control benefits can be improved by implementing internal controls using an ERP system equipped with internal control mechanisms.

Practically, the structure and analytical results of this study can be used not only as references for improving the ERP system internal control benefits of an enterprise, but they can also be employed to improve information system quality, promote user satisfaction, and create competitive advantages for ERP information service suppliers. For academic research, this study can be used as a reference for wider discussion and model inferences in the future.

\section{References}

Al-Mashari, M., Al-Mudimigh, A., \& Zairi, M. (2003). Enterprise Resource Planning: A Taxonomy of Critical Factors. European Journal of Operations Research, 146(2), 352-364. http://dx.doi.org/10.1016/S0377-2217(02)00554-4

Bailey, J. E., \& Pearson, S. W. (1983). Development of a Tool for Measuring and Analyzing Computer User Satisfaction. Management Science, 29, 530-545. http://dx.doi.org/10.1287/mnsc.29.5.530

Baroudi, J. J., \& Orlikowski, W. J. (1988). A Short-Form Measure of User Information Satisfaction: A Psychometric Evaluation and Note on Use. Journal of Measurement Information Systems, 4(4), 44-59.

Bradford, M., \& Florin, J. (2003). Examining the Role of Innovation Diffusion Factors on the Implementation Success of Enterprise Resource Planning Systems. International Journal of Accounting Information Systems, 4, 205-225. http://dx.doi.org/10.1016/S1467-0895(03)00026-5

Brynjolfsson, E. (1993). The Productivity Paradox of Information Technology. Communications of the ACM, 36(12), 67-77. http://dx.doi.org/10.1145/163298.163309 
Brynjolfsson, E., \& Hitt, L. M. (1996). Paradox Lost? Firm-level Evidence on the Return so Information Systems Spending. Management Science, 42(4), 541-558. http://dx.doi.org/10.1287/mnsc.42.4.541

Chand, D., Hachey, G., Hunton, J., Owhoso, V., \& Vasudevan, S. (2005). A balanced scorecard based framework for assessing the strategic impacts of ERP systems. Computers in Industry, 56(6), 558-572. http://dx.doi.org/10.1016/j.compind.2005.02.011

Debreceny, R. S., Gray, G. L., Ng, J. J. J., Lee, K. S. P., \& Yau, W. F. (2005). Embedded Audit Modules in Enterprise Resource Planning System: Implementation and Functionality. Journal of Information Systems, 19(2), 7-27. http://dx.doi.org/10.2308/jis.2005.19.2.7

DeLone, W., \& McLean, E. (2004). Measuring e-Commerce Success: Applying the DeLone \& McLean Information Systems Success Model. International Journal of Electronic Commerce, 9(1), 31-47.

DeLone, W. H., \& McLean, E. R. (2003). The DeLone \& McLean Model of Information System: A Ten-Year Update. Journal of Management Information System, 19(4), 9-30.

DeLone, W. H., \& McLean, E. R. (1992). Information Systems Success: The Quest for the Dependent Variable. Information Systems Research, 3(1), 60-95. http://dx.doi.org/10.1287/isre.3.1.60

Dos, S. B., Peffers, L. K., \& Mauer, D. C. (1993). The Impact of Information Technology Investment Announcements on the Market Value of the Firm. Information Systems Research, 4(1), 1-23. http://dx.doi.org/10.1287/isre.4.1.1

Eakins, S. G. (2002). In D. Clinton (Ed.), Finance, Investment, Institutions, and Management (2nd ed.). New York: Addison Wesley.

Hayes, D. C., Hunton, J. E., \& Reck, J. L. (2001). Market Reaction to ERP Implementation Announcements. Journal of Information Systems, 15(1), 3-18. http://dx.doi.org/10.2308/jis.2001.15.1.3

Hunton, J. E., McEwen, R. A., \& Wier, B. (2002). The Reaction of Financial Analysts to Enterprise Resource Planning (ERP) Implementation Plans. Journal of Information Systems, 16(1), 31-40. http://dx.doi.org/10.2308/jis.2002.16.1.31

Hunton, J. E., Libby, R., \& Mazza, C. L. (2006). Financial Reporting Transparency and Earnings Management. The Accounting Review, 81(1), 135-157. http://dx.doi.org/10.2308/accr.2006.81.1.135

Ives, B., Olson, M. H., \& Baroudi, J. J. (1983). The Measurement of User Information Satisfaction. Communications of the ACM, 26(10), 785-793. http://dx.doi.org/10.1145/358413.358430

Jeong, M., \& Lambert, C. U. (2001). Adaptation of An Information Quality Framework to Measure Customer's Behavioral Intentions to Use Loading Web Sites. Hospitality Management, 20(1), 129-146. http://dx.doi.org/10.1016/S0278-4319(00)00041-4

Lambert, R. A. (2001). Contracting Theory and Accounting. Journal of Accounting \& Economics, 32, 3-87. http://dx.doi.org/10.1016/S0165-4101(01)00037-4

Little, A., \& Best, P. J. (2003). A Framework for Separation of Duties in an SAP R/3 Environment. Managerial Auditing Journal, 18(5), 419-430. http://dx.doi.org/10.1108/02686900310476882

Markus, A., Petrie, M. S., \& Tanis, D. S. (2000). Learning from Adopter's Experience with ERP: Problems Encountered and Success Achieved. Journal of Information Technology, 15(4), 245-265. http://dx.doi.org/10.1080/02683960010008944

Poston, R., \& Grabski, S. (2001). Financial Impacts of Enterprise Resource Planning Implementations. International Journal of Accounting Information Systems, 2(4), 271-294. http://dx.doi.org/10.1016/S1467-0895(01)00024-0

Rai, A., Lang, S. S., \& Welker, R. B. (2002). Assessing the Validity of IS Success Models: An Empirical Test and Theoretical Analysis. Information Systems Research, 13(1), 50-69. http://dx.doi.org/10.1287/isre.13.1.50.96

Ragowsky, A., \& Adams, D. A. (2005). Assessing the Value Provided by ERP Applications Through Organizational Activities. Communications of the Association for Information Systems, 16, 381-406.

Newstrom, J. W., \& Davis, K. (1989). Human Behavior at Work: Organizational Behavior. New York: McGraw Hill.

Richman, B. M., \& Farmer, R. N. (1975). Management and Organizations. New York: Random House Press. 
Wright, S., \& Wright, A. M. (2002). Information System Assurance for Enterprise Resource Planning Systems: Unique Risk Considerations. Journal of Information Systems, 16, 99-113. http://dx.doi.org/10.2308/jis.2002.16.s-1.99

\section{Notes}

Note 1. Information source: Survey of investments on commercial software by large enterprises in Taiwan, a research report by the Market Intelligence and Consulting Institute, Institute for Information Industry, Wen-Yi Chen, Document code: CDOC20100507008; 2010.

Note 2. Article 6 of the Regulations Governing Establishment of Internal Control Systems by Public Companies also specifies the components included in internal control.

Note 3.Such as Management Science, MIS Quarterly, Communication of the ACM, Decision Science, Information \& Management, Journal of MIS, and ICIS Proceeding.

Note 4. Article 6 of the Regulations Governing Establishment of Internal Control Systems by Public Companies also specifies the components included in internal control.

\section{Copyrights}

Copyright for this article is retained by the author(s), with first publication rights granted to the journal.

This is an open-access article distributed under the terms and conditions of the Creative Commons Attribution license (http://creativecommons.org/licenses/by/3.0/). 